\title{
Registro de imágenes video-endoscópicas para reconstruir cartografías de órganos huecos
}

\author{
Video-Endoscopic Image Registration \\ for Cartography Reconstruction of Hollow Organs
}

\author{
Miranda-Luna R. \\ Universidad Tecnológica de la Mixteca, Oaxaca \\ E-mail:rmiranda@yahoo.com \\ Posada-Gómez R. \\ Departamento de Posgrado e Investigación \\ Instituto Tecnológico de Orizaba, Veracruz \\ E-mail:rposada@itorizaba.edu.mx \\ Alor-Hernández G. \\ Departamento de Posgrado e Investigación \\ Instituto Tecnológico de Orizaba, Veracruz \\ E-mail:galor@itorizaba.edu.mx
}

\author{
Martínez-Sibaja A. \\ Departamento de Posgrado e Investigación \\ Instituto Tecnológico de Orizaba, Veracruz \\ E-mail:asibaja@itorizaba.edu.mx \\ Cortés-Robles G. \\ Departamento de Posgrado e Investigación \\ Instituto Tecnológico de Orizaba, Veracruz \\ E-mail:grobles@itorizaba.edu.mx
}

Información del artículo: recibido: septiembre de 2006, reevaluado: noviembre de 2007, aceptado: septiembre de 2010

\section{Resumen}

Los sistemas video-endoscópicos se usan para examinar órganos huecos permitiendo observar las capas que recubren las cavidades internas de los órganos (superficies internas). Comúnmente, un especialista debe analizar la secuencia de imágenes adquiridas durante el examen endoscópico, ya sea para confirmar el diagnóstico efectuado durante la endoscopia o para valorar la evolución de una patología. En una secuencia de imágenes videoendoscópicas (en donde cada imagen muestra una pequeña área de la superficie tisular examinada), puede resultar difícil localizar el área de interés debido a: 1) la gran cantidad de imágenes que componen la secuencia, 2) la naturaleza secuencial del archivo (que obliga al médico a repasar toda la secuencia para poder encontrar la zona de interés) y 3) la posibilidad de que la zona de interés se encuentre o esté contenida en varios tramos no contiguos de la secuencia. En este trabajo, se implementa una metodología que permite la reconstrucción automática de una cartografía de la región de interés, permitiendo su visualización panorámica y eliminando información redundante. Además, se presenta un método basado en un algoritmo automático de registro de imágenes para la reconstrucción de cartografías. Finalmente, se presenta un protocolo de evaluación y los resultados obtenidos.

\section{Descriptores}

- cartografías de órganos internos

- video-endoscopia

- registro de imágenes

- corrección de la distorsión radial 


\begin{abstract}
In examinations of hollow organs, video-endoscopic systems are used. These systems allow to analyze layers recovering the internal organ cavities (internal surfaces). In this kind of analysis, an expert must review the acquired image sequence during an endoscopic analysis, either to confirm the diagnosis issue of endoscope, or to evaluate the pathology's evolution. For these reasons, it is difficult to find the surface of interest in a video-endoscopic image sequence (where each image shows a little area of examined tissue surface) due to: (1) the big number of images into the sequence, (2) the sequential nature of file (forcing doctor to review all sequence to find the interest region), and (3) frequently the interest region that could be physically contiguous is shown in frames far-away from each other. In this work, a methodology for automatic cartography reconstruction of the interest region is proposed. This methodology provides a panoramic view and eliminates redundant information. Furthermore, an automatic image registration algorithm for cartography construction is presented. Finally, an evaluation protocol and the obtained results are also presented.
\end{abstract}

Keywords

- internal organs cartography

- video-endoscopy

- image registration

- radial distortion correction

\section{Introducción}

Actualmente, los sistemas video-endoscópicos utilizados en aplicaciones médicas generan secuencias de imágenes en los que cada cuadro contiene un fragmento de la superficie total escaneada. Una cartografía (por la analogía con el trazado de mapas geográficos) del área escaneada, constituye así una representación fácil de manejar, la cual es útil en un análisis post-operatorio. En una secuencia de video, las imágenes adyacentes comparten una superficie común (información redundante) que permiten construir el panorama de la superficie observada utilizando las imágenes de la secuencia. Para construir cartografías a partir de imágenes sucesivas, se propone efectuar un registro de estas imágenes y combinarlas para constituir la imagen panorámica.

El registro de imágenes endoscópicas se ve afectado por tres características inherentes a la naturaleza de las imágenes adquiridas (figura 1 ):

1) La distorsión geométrica no lineal de tipo radial causada por un sistema óptico diseñado para brindar un amplio campo de visión distorsiona las imágenes haciendo que un mismo punto de la escena ocupe posiciones relativas diferentes en dos imágenes sucesivas a causa de esta distorsión (Tian et al., 2002), (Smith et al., 1992);

2) El patrón fijo de alta frecuencia introducido por la fibra óptica de los fibroscopios (endoscopios que utilizan fibras ópticas para recuperar la imagen) y que corresponde al arreglo de las fibras, se superpone a la imagen generada $y$;

3) Un patrón de baja frecuencia generado por una iluminación no uniforme al interior del órgano (normalmente más importante en el centro que en los extremos de la imagen).
En este trabajo se presenta un método para reconstruir una cartografía de un órgano explorado a través de un registro monomodal.

La estructura de este trabajo es la siguiente: primero, se describe la implementación de un método de registro que corrige las distorsiones propias al sistema de adquisición y efectúa la cartografía de una región de interés. Después, se describe la metodología empleada en el desarrollo de la cartografía explicando cada etapa involucrada en este proceso. Posteriormente, se describen las pruebas efectuadas al sistema y los resultados obtenidos. Finalmente, se presenta la conclusión donde se analizan los resultados y se discuten las posibilidades del sistema propuesto.

\section{Metodología para la creación de la cartografía}

La metodología para la realización de la cartografía se divide en tres etapas principales:

1. El acondicionamiento de las imágenes que corrige la distorsión radial y reduce la presencia de los patrones de alta y baja frecuencia;

2. El registro de las imágenes previamente corregidas usando un algoritmo automático basado en la información mutua de las imágenes y;

3. La creación de la imagen panorámica conteniendo todas las imágenes registradas en un mismo referencial.

\section{Acondicionamiento de las imágenes endoscópicas}

Para reducir los problemas que afectan el registro de las imágenes se procede a acondicionar las imágenes efectuando primeramente la corrección de la distorsión radial (mediante un algoritmo de registro de imágenes) y 
filtrando posteriormente las imágenes resultantes para eliminar los patrones de alta y baja frecuencia.

A continuación, se describen las técnicas empleadas en la metodología propuesta para corregir los principales tipos de distorsión generada por el endoscopio (la distorsión radial y la corrección de patrones de alta y baja frecuencia).

\section{Corrección de la distorsión radial}

La transformación geométrica que relaciona las imágenes adquiridas a través del endoscopio, se afecta tanto por la posición del endoscopio desde la cual se adquieren como por la óptica del endoscopio. La distorsión radial que afecta las imágenes endoscópicas (figura 1a) se modela con las coordenadas de la proyección del centro óptico en la imagen $(C x, C y)$ y la relación polinomial $r^{\prime}$ expresada en la siguiente fórmula:

$r^{\prime}=\sum_{i=1}^{M} k_{i} \cdot r^{i} \quad$ con $k_{1}=1$

donde

$r$ es la distancia radial entre un punto de coordenadas $(x, y)(C x, C y)$

$k_{i}$ son los coeficientes de corrección usados para obtener una imagen sin distorsión,

$M$ es el grado del polinomio.

El número de parámetros $k_{i}$ que deben calcularse depende de la importancia de la distorsión, así como de la precisión requerida. En este trabajo, se seleccionó $M=5$ que representa un buen compromiso entre exactitud y tiempo de procesamiento.

El problema de la corrección radial se observa como un problema de calibración del endoscopio. Así, sea $U$ una imagen ideal libre de deformaciones, se considera que la imagen $V$ es la imagen $U$ adquirida por medio

a)
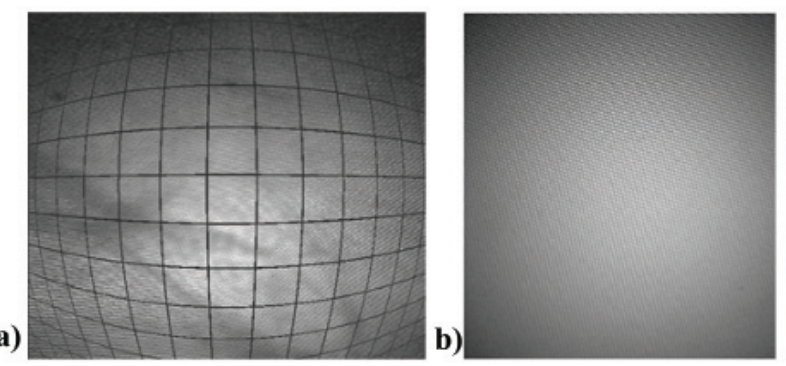

Figura 1. Características que impiden el registro de imágenes endoscópicas, a) Deformación radial (indicada con una rejilla distorsionada superpuesta a la imagen endoscópica), b) Patrones de alta y baja frecuencia creados por las fibras ópticas del fibroscopio y la falta de uniformidad de la iluminación en el interior del órgano. del endoscopio a calibrar y se afectó por una transformación $T$, a su vez conformada por una transformación $T_{i}$ (parámetros intrínsecos del endoscopio) dada por la distorsión radial y una transformación $T_{e}$ (parámetros extrínsecos) causada por la posición desde la cual se efectuó la adquisición de la imagen $U$, de manera que:

$V=T U=T_{e} T_{i} U$

De esta manera, efectuando un registro entre las imágenes $U$ y $V$ se calculan los valores de la matriz $T$. Los parámetros de la matriz proyectiva (traslaciones: $t x, t y$, rotación: $\theta$, escala: $\alpha)$ y del polinomio $\left(C x, C y\right.$ y $\left.k_{i}\right)$ son independientes; de esta forma, los parámetros de corrección radial se aíslan después del registro, con el fin de aplicar la corrección radial de manera sistemática a todas las imágenes adquiridas con el endoscopio, siempre y cuando no se modifique la óptica del mismo. Una explicación detallada del procedimiento de corrección radial o calibración del endoscopio se encuentra en (Miranda et al., 2004).

Una vez corregida la distorsión radial en toda la secuencia de imágenes, se procede a reducir la presencia de los artefactos de alta y baja frecuencia generados por el arreglo de fibras ópticas y la iluminación no uniforme, respectivamente.

Reducción de la presencia de patrones de alta y baja frecuencia

La reducción de la presencia de los patrones de alta y baja frecuencia se obtiene filtrando la imagen. Para eliminar las altas frecuencias añadidas a las imágenes por el arreglo de fibras ópticas (figura 1b), se emplea un filtro con una función gaussiana, cuya función de transferencia en el dominio de la frecuencia (González, 2002) se expresa como:

$H(u, v)=e^{-D^{2(u, v) / 2 D_{2}^{0}}}$

donde

$D(u, v)$ es la distancia espacial desde la componente de frecuencia $(u, v)$ hasta el centro del espectro $(u=0, v=0) \mathrm{y}$;

$D_{0} \quad$ es la desviación estándar del filtro.

Una vez analizado el espectro de Fourier correspondiente al patrón de fibras, se fija $D_{0}=4$, obteniendo así un filtro para bajas. Para corregir el problema de la iluminación no uniforme, primero se obtiene una versión filtrada de la imagen endoscópica conteniendo las componentes de muy baja frecuencia, producidas esencial- 
mente por la distribución no uniforme de la iluminación, mediante el filtro gaussiano con $D_{0}=16$. La imagen obtenida se resta de la imagen previamente filtrada con $D_{0}=4$. De esta manera, se tiene una imagen corregida que finalmente se utiliza en el registro de imágenes.

\section{Registro de imágenes}

El registro de imágenes se efectúa con pares de imágenes en niveles de gris. Dadas dos imágenes $U$ y $V$, su registro se expresa como:

$\widetilde{T}=\underset{T}{\arg \operatorname{opt}} S\left[f_{m}(U), f_{t}(T(V))\right]$

En la fórmula (4), $\tilde{T}$ representa la transformación buscada en el espacio de transformaciones $T$, es decir, la transformación que optimiza la medida de similitud $S$ calculada con las estructuras homologas extraídas de las imágenes $U$ y $V$ con ayuda de algoritmos de segmentación representados por $f_{t}$ y $f_{m}$.

El algoritmo de registro emplea los niveles de grises como estructuras homologas, evitando la necesidad de efectuar una segmentación de las imágenes. En este trabajo, se implementó como medida de similitud la información mutua (Viola, 1995). Sea $W$ el resultado de la transformación $T$ aplicada sobre la imagen $V$, la información Mutua $I(U, W)$ se expresa por la siguiente fórmula:

$I(U, W)=H(U)+H(W)-H(U, W)$

donde

$H(U)$ y $H(W)$ representan la entropía de las imágenes $U$ y $W$, respectivamente dadas por:

$H(x)=-\sum_{x_{n} \in \Omega x} P\left(x_{n}\right) \log _{a}\left[P\left(x_{n}\right)\right]$

donde

$x_{n}$ es el $n^{\text {esimo }}$ valor del espacio $\Omega x(\Omega x$ es el intervalo de niveles de gris $\in[0-255])$.

$H(U, W)$ representa la entropía conjunta de las imágenes y se define como:

$H(x, y)=-\sum_{x_{n}, y_{n} \in \Omega x, y} \log _{a}\left[P\left(x_{n}, y_{n}\right) \cdot P\left(x_{n}, y_{n}\right)\right]$

donde:

$x_{n}$ y $y_{n}$ son los $n^{\text {ésimos }}$ valores de $\Omega x$ y $\Omega y$ (niveles de gris: 0 - 255) para las variables $x$ y $y$.
$P\left(x_{n}, y_{n}\right)$ es la probabilidad de concurrencia de los eventos $x_{n}, y_{n}$.

La información mutua es una medida de similitud robusta que permite conocer la información que comparten las partes superpuestas de dos imágenes caracterizadas únicamente por la distribución de sus niveles de gris. Esta medida de similitud es poco sensible a los problemas de áreas con poco recubrimiento espacial común al utilizar, tanto la entropía de cada imagen como la entropía conjunta de ambas.

El modelo de transformación usado considera translaciones, rotaciones, factor de escala y perspectiva (que representan los cambios que pueden darse entre dos imágenes consecutivas por la manipulación del endoscopio). Para la optimización de los parámetros de la matriz de transformación que permiten optimizar la información mutua, se implementó el algoritmo de gradiente descendente estocástico, debido a la existencia de mínimos locales en el espacio de búsqueda generados esencialmente por la interpolación de los niveles de gris. Este algoritmo es un método de optimización iterativo bien adaptado para superar los pequeños óptimos locales capaces de impedir la convergencia global. Los valores iniciales de la matriz de transformación son los de la matriz identidad y se actualizan en cada iteración, de manera que:

$T(i+1)=T(i)+\lambda \frac{\partial I[U, T(i) V]}{\partial T}$ en el $(i+1)^{\text {śsimo }}$ paso

donde $\lambda$ es el parámetro de rapidez de convergencia, el cual se reduce progresivamente a medida que se alcanza el máximo de la información mutua.

El registro se efectúa entre pares de imágenes consecutivos en la secuencia generada por el de video-endoscopio. Una vez hecho esto, es necesario que todas las imágenes transformadas después del registro se sitúen en un referencial común para construir la cartografía.

\section{Creación del mosaico}

El proceso de registro entre pares de imágenes consecutivas genera una matriz de transformación Tr que optimiza la información mutua de dos imágenes adyacentes $i$ e $i-1$. Posteriormente, se calcula para cada imagen la transformación global $\mathrm{Tg}$ que permita tener todas las imágenes en un mismo sistema de coordenadas, mediante la ecuación:

$\operatorname{Tg}(i)=\operatorname{Tr}(i, i+1) \times \operatorname{Tg}(i-1)$ para la $i^{\text {śima }}$ imagen

Esto permite situar todas las imágenes en el referencial de la primera imagen. Después de aplicar la transforma- 
ción global a todas las imágenes, sólo resta combinarlas para formar una sola imagen que constituye el panorama de toda la superficie explorada (cartografía 2D).

\section{Pruebas efectuadas}

Con el fin de validar el método de creación de cartografías y las diferentes etapas que lo componen, se efectuaron pruebas para determinar la eficiencia en la corrección de la distorsión radial. Así también, se efectuó la reconstrucción de una cartografía a partir de imágenes adquiridas empleando un sistema de posicionamiento que permite conocer los desplazamientos reales del endoscopio y una imagen panorámica que simula la superficie de la cavidad interna a explorar. Al tratarse de una imagen bidimensional se efectúa una comparación precisa con los resultados de la cartografía reconstruida.

\section{Sistema de posicionamiento}

Con el fin de conocer los desplazamientos efectuados por el endoscopio al momento de la adquisición de la secuencia de imágenes, se construyó un sistema de posicionamiento (figura 2) constituido por una plataforma en la que se montaron 3 tablas micrométricas (NEWPORT modelo MUMR8.51). Las tablas se ensamblaron de manera tal que permiten obtener desplazamientos lineales en los 3 ejes $(\vec{x}, \vec{y}, \vec{z})$. El equipo de posicionamiento permite controlar de manera precisa los desplazamientos manualmente efectuados del endoscopio dentro de un volumen de $50 \times 50 \times 40 \mathrm{~mm}^{3}$.

Para la adquisición de las imágenes, se empleó una cámara Leritier 760 ULL y un fibroscopio (FUJINON

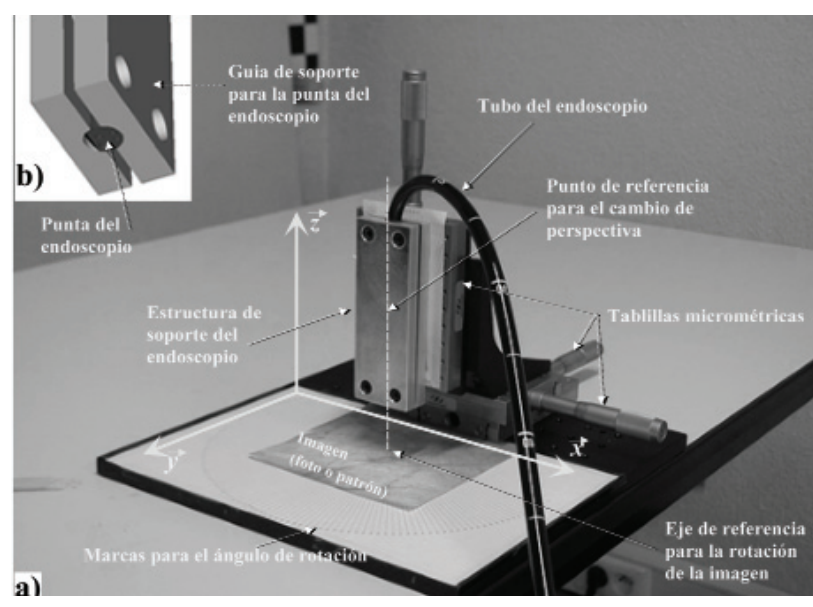

Figura 2. Sistema de posicionamiento, a) ubicación de los diversos componentes del sistema de posicionamiento, b) vista detallada de la guía que sujeta la punta del fibroscopio.
FG-100FP), el cual se fijó al sistema de posicionamiento con ayuda de una guía (figura 2 b). De esta manera, la punta del endoscopio se alinea con el borde de la guía. El sistema permite colocar la punta del endoscopio a cualquier distancia entre $10 \mathrm{~mm}$ y $60 \mathrm{~mm}$ con respecto a la escena. Además, el sistema permite girar el endoscopio para simular adquisiciones perspectivas. En la parte inferior del sistema se sitúa la imagen a adquirir (fotografía de la región a explorar o patrón para evaluar cuantitativamente la calibración). La imagen a adquirir puede rotarse alrededor del eje $\vec{z}$ a pasos de $2^{\circ}$, debido a un pivote que se encuentra en el centro de la base de adquisición y a un patrón con marcas colocado debajo de la imagen.

El sistema descrito permite efectuar, tanto las pruebas de la calibración como de la reconstrucción de la cartografía.

\section{Calibración del endoscopio \\ (corrección de la distorsión radial)}

Para evaluar el método de corrección de la distorsión radial, se utilizó una imagen patrón (figura 3a). La imagen patrón, se adquirió situando el endoscopio perpendicular a ésta. El posicionamiento del endoscopio se efectuó empleando el sistema de posicionamiento antes descrito.

Para la corrección de distorsión radial, se inicializan los parámetros del polinomio $k_{i}=0$ y $C x$ y $C y$ toman las coordenadas del centro de la imagen. La matriz proyectiva, se inicializa con $t x=t y=1, \theta=0$ y $\alpha=0.85$.

El error en la corrección de la distorsión radial se evalúa calculando la distancia euclidiana entre puntos

b)

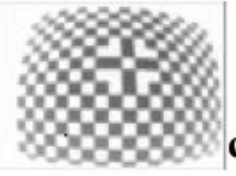

a)
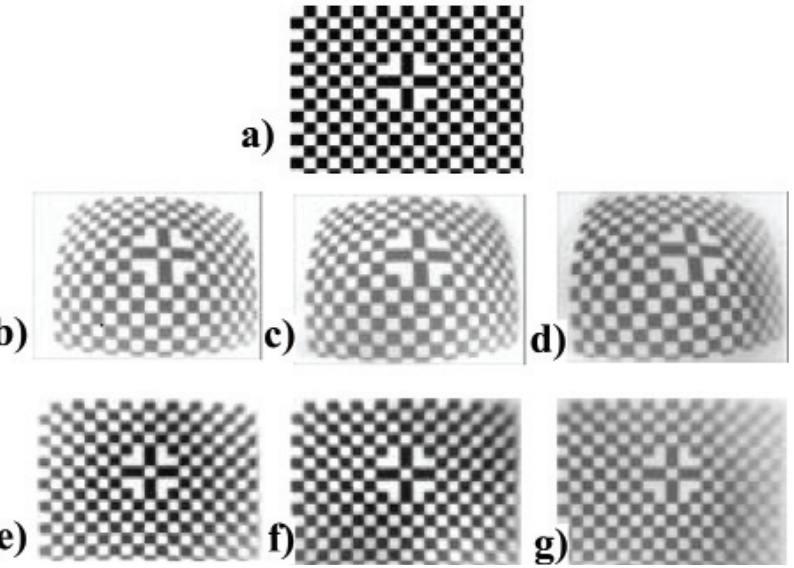

Figura 3. Resultados de la corrección radial, a) patrón de calibración, adquisiciones endoscópicas del patrón a, b) $0^{\circ}$, c) $5^{\circ}$, d) $10^{\circ}$, e) corrección de la imagen b, f) corrección de la imagen c, g) corrección de la imagen d. 
de referencia identificados, tanto en la imagen patrón sin distorsión como en la imagen endoscópica binarizada. Estos puntos se definen por los centros de los cuadros blancos.

Con el fin de evaluar la influencia del ángulo de perspectiva en el método de calibración, se realizaron (con ayuda del sistema de posicionamiento) adquisiciones de la imagen patrón a diferentes ángulos $\left(0^{\circ}, 5^{\circ} \mathrm{y}\right.$ $10^{\circ}$ ), para generar las perspectivas con respecto a la perpendicular al plano del patrón.

Debido a que el campo de visión del endoscopio se calculó en 449 píxeles, finalmente se normalizan los errores promedio $\left(e_{\text {prom }}\right)$ y máximos $\left(e_{\operatorname{mix}}\right)$ que representan el comportamiento típico del sistema y el peor escenario, respectivamente (Shahidi et al., 2002).

\section{Adquisición y reconstrucción de una secuencia}

Empleando el sistema de posicionamiento se adquirió una secuencia de imágenes, simulando una exploración de endoscopia. Primeramente, se colocó sobre la plataforma la imagen a adquirir. Durante la adquisición, el endoscopio se situó a una altura de $40 \mathrm{~mm}$ con respecto a la plataforma. Posteriormente, se adquirieron 20 imágenes, desplazando progresivamente la punta del endoscopio de izquierda a derecha (dirección positiva del eje horizontal) (figura 4a). Cada imagen se adquirió después de un desplazamiento de $2.5 \mathrm{~mm}$. Este valor representa el desplazamiento máximo de la punta del endoscopio durante un examen de endoscopia clínica (se determinó de manera empírica tomando en cuenta la frecuencia de adquisición de 25 cuadros por segundo). Esta secuencia permite probar la respuesta del algoritmo, ante un desplazamiento puro.

A partir de la última posición (imagen $I_{20}$ ) se efectúa una segunda etapa de 10 adquisiciones, en las que la punta del endoscopio se desplaza en dirección diagonal sobre el plano $(\vec{x}, \vec{y})$ con incrementos de $-2.5 \mathrm{y}-2.5 \mathrm{~mm}$, respectivamente, a lo largo de cada eje. Estos desplazamientos se acompañaron de rotaciones de la imagen alrededor del eje $\vec{z}$ de $+2^{\circ}$ entre cada adquisición. Finalmente, se efectuaron 10 adquisiciones desplazando el endoscopio de forma diagonal sobre el plano $(\vec{x}, \vec{y})$ con incrementos de $-2.5 \mathrm{y}+2.5 \mathrm{~mm}$, respectivamente a lo largo de cada eje, al mismo tiempo se efectuaron rotaciones alrededor de los ejes $\vec{y}$ y $\vec{z}$ de $2^{\circ}$ y $-2^{\circ}$, respectivamente, produciéndose así un efecto de perspectiva en las imágenes.

Para evaluar el método propuesto, se efectuó primeramente la adquisición de una secuencia utilizando una fotografía digital de la superficie interna de la vejiga de un puerco (figura 4a) y posteriormente un diseño cons-
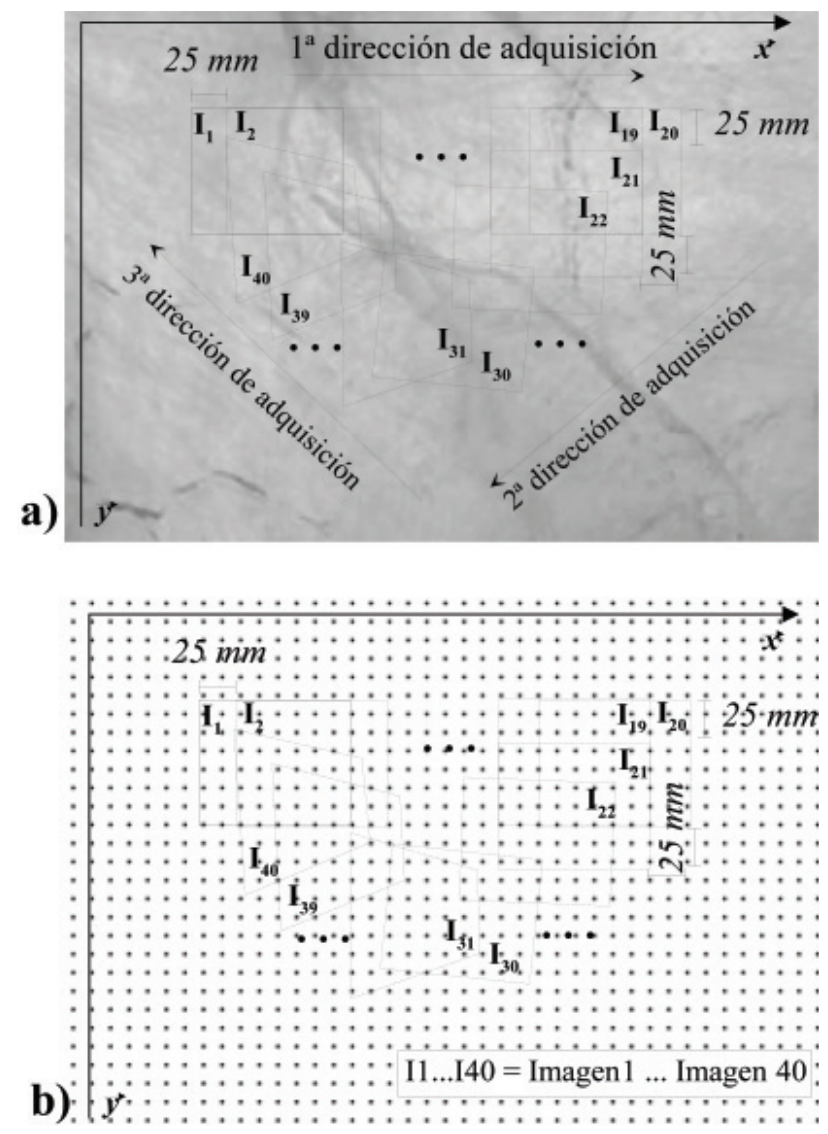

Figura 4. Protocolo de adquisición de la secuencia de evaluación, a) fotografía de la superficie interna de la vejiga de un puerco, sobre la cual se indica el camino seguido durante las adquisiciones de acuerdo al protocolo establecido, b) patrón de prueba utilizado para evaluar la calidad de la cartografía reconstruida, constituido de marcas alineados en forma de rejilla y con una separación de $10 \mathrm{~mm}$ entre cada fila.

tituido de cuadros alineados en forma de rejilla con una separación de $10 \mathrm{~mm}$ entre cada línea (figura $4 \mathrm{~b}$ ). Las 40 imágenes de la primera adquisición (fotografía de la vejiga) se registraron con el fin de obtener los parámetros de transformación. Los parámetros de transformación obtenidos con la primera prueba se aplicaron a la segunda secuencia (patrón de puntos), a fin de reconstruir la cartografía de dicho patrón. La calidad de la cartografía de la primera adquisición (vejiga) se evalúa así, comparando el patrón de puntos reconstruido contra el patrón de puntos original. El error se calcula como la suma de las distancias euclidianas entre los centros de puntos correspondientes del patrón reconstruido y del patrón original, esto se expresa mediante la siguiente ecuación:

$e=\sum_{i=1}^{N} \sqrt{x_{i}^{2}+y_{i}^{2}} ; x_{i}=\left|x_{0}-x_{r}\right|_{i} ; y=\left|y_{0}-y_{r}\right|_{i}$ 
donde

$N$ representa los puntos a comparar,

$x_{i}$ y $y_{i}$ son los valores absolutos de los errores en las direcciones vertical y horizontal entre el centro del iésimo punto en el patrón original y su correspondiente en el mosaico reconstruido.

\section{Resultados}

\section{Corrección de la distorsión radial}

La tabla 1 muestra los valores de los parámetros calculados por el algoritmo de calibración para la imagen patrón adquirida desde 3 ángulos diferentes (figura 3). Los valores de $k_{4}$ y $k_{5}$ son similares independientemente del ángulo de adquisición, lo cual confirma la irrelevancia del ángulo de perspectiva. Se realizó una comparación de los errores normalizados obtenidos para todas las imágenes con el fin de evaluar con mayor exactitud la influencia del ángulo de inclinación obteniendo un error promedio $e_{\text {prom }}$ de 0.21 a $0.34 \%$. Los valores del error máximo $e_{\text {máx }}$ son de 2 a 4 veces mayores que $e_{\text {prom }}$. Sin embargo, los errores obtenidos son comparables con otros resultados (Asari et al., 1999).

De esta manera, el método propuesto sólo requiere que el endoscopio se posicione de manera perpendicular al patrón de la figura 3a para efectuar la calibración, el error final de la reconstrucción de la cartografía no varía, aún cuando se haya adquirido la imagen en un rango de $10^{\circ}$.

Tabla 1. Resultados de la corrección radial. $k_{i}$, Cx, y Cy son los coeficientes de corrección radial (sin dimensión) y las coordenadas del centro óptico (en pixeles). $e_{\text {prom }} e_{\text {máx }}$ son los errores promedio y máximo, respectivamente, dados en pixeles y normalizados (\% del diámetro del campo de visión).

\begin{tabular}{|c|c|c|c|c|}
\hline \multicolumn{2}{|c|}{ Parámetro Ángulo } & $0^{\circ}$ & $5^{\circ}$ & $10^{\circ}$ \\
\hline \multicolumn{2}{|c|}{$k_{2} \times 10^{-4}$} & 5.36 & 3.12 & 5.59 \\
\hline \multicolumn{2}{|r|}{$k_{3} \times 10^{-6}$} & 1.42 & 1.92 & 1.09 \\
\hline \multicolumn{2}{|c|}{$k_{4} \times 10^{-8}$} & 2.46 & 2.69 & 2.32 \\
\hline \multicolumn{2}{|c|}{$k_{5} \times 10^{-11}$} & 6.54 & 6.18 & 6.28 \\
\hline \multicolumn{2}{|c|}{$C x$} & 190.2 & 187.7 & 188.5 \\
\hline \multicolumn{2}{|r|}{$C y$} & 118.9 & 117.5 & 121.0 \\
\hline \multirow{2}{*}{$e_{\text {prom }}$} & pixeles & 1.33 & 1.52 & 0.94 \\
\hline & $\%$ FOV & 0.30 & 0.34 & 0.21 \\
\hline \multirow{2}{*}{$e_{\operatorname{máx}}$} & pixeles & 3.70 & 4.73 & 3.68 \\
\hline & $\%$ FOV & 0.84 & 1.07 & 0.83 \\
\hline
\end{tabular}

Eliminación de los patrones

de alta y baja frecuencia

Los resultados del filtro aplicado a las imágenes adquiridas para eliminar las componentes correspondientes al patrón de fibras y la iluminación no homogénea se muestran en la figura 5. Aunque la calidad visual de la imagen después del filtrado no resulta apropiada para un análisis visual, la información que contiene es adecuada para su uso en el procedimiento de registro, por lo que una vez calculado los parámetros de la transformación pueden aplicarse a las imágenes sin filtrar y permitir una mejor visualización de la cartografía.

\section{Reconstrucción de la cartografía (Mosaico)}

El mosaico mostrado en la figura 6 se construyó a partir de una secuencia de 40 imágenes en niveles de gris de tamaño $320 \times 385$ píxeles adquiridas, situando la punta del endoscopio a $40 \mathrm{~mm}$ de altura. La figura 7 muestra la reconstrucción del patrón de prueba utilizado para la evaluación cuantitativa del método de registro. El error promedio obtenido entre imágenes adyacentes fue de 0.09 píxel para la translación en el eje $\vec{x},-0.33$ píxel para la translación en el eje $\vec{y}, 0.001$ para el factor de escala y $0.073^{\circ}$ para el ángulo de rotación. El error global de reconstrucción del mosaico (error entre el patrón a)

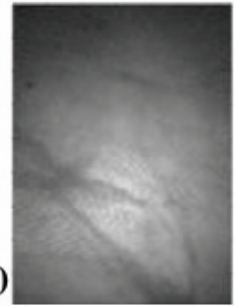

d)

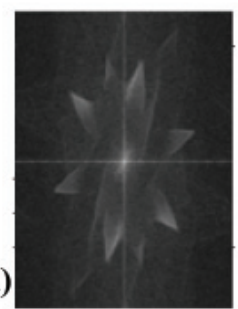

b)

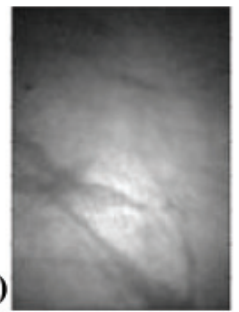

c)

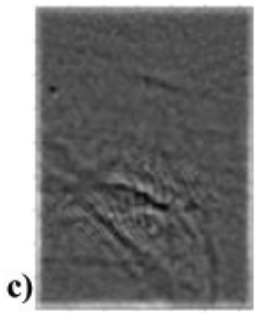

e)

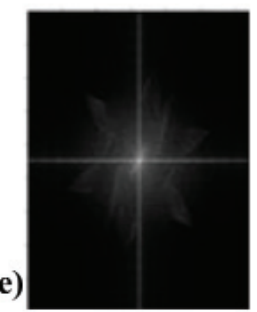

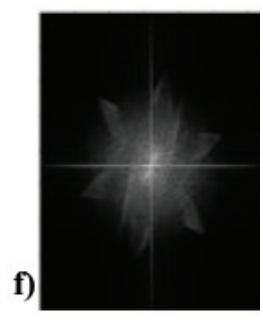

Figura 5. Eliminación de los patrones de alta y baja frecuencia, a) Imagen video-endoscópica original en niveles de gris,

b) Imagen después de eliminar las componentes de alta frecuencia correspondientes a las fibras ópticas,

c) Imagen después de eliminar el patrón de baja frecuencia creado por la iluminación no-homogénea,

d) Espectro de Fourier de la imagen a,

e) Espectro de Fourier de la imagen b y

f) Espectro de Fourier de la imagen c. 


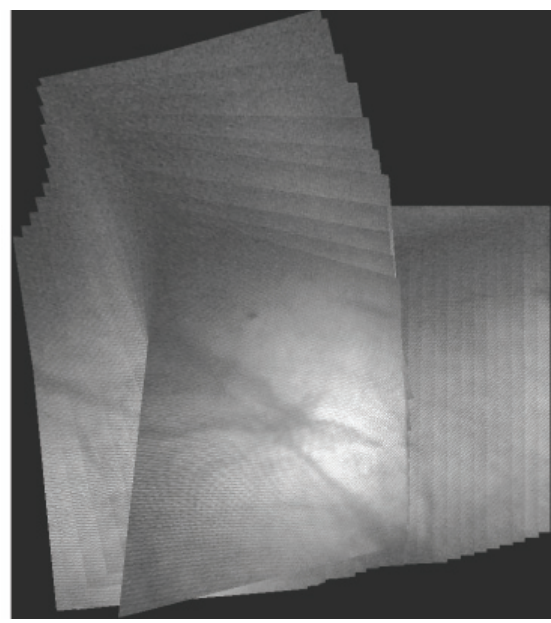

Figura 6. Mosaico reconstruido a partir de una secuencia de 40 imágenes endoscópicas (en niveles de gris) de la vejiga de un puerco.

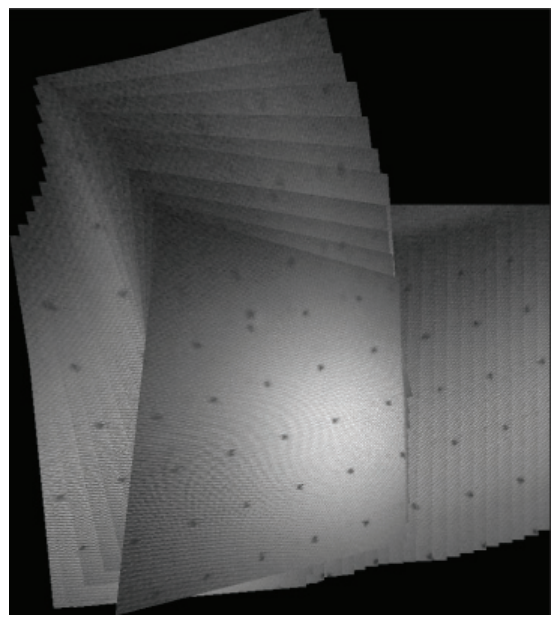

Figura 7. Reconstrucción del patrón a partir de 40 imágenes endoscópicas (en niveles de gris), usando los parámetros de transformación obtenidos durante el proceso de registro de las imágenes de la vejiga del puerco.

original y el patrón reconstruido) fue de 6.37 pixeles para el error promedio, con un error mínimo y máximo de 1.1 y 30.1053 pixeles, respectivamente. Para efectuar el registro entre 2 imágenes se requirió aproximadamente 250 iteraciones (aproximadamente 3 minutos utilizando una Pentium III a $850 \mathrm{MHz}$ y $64 \mathrm{Mb}$ de RAM). Cabe mencionar que se si el grado de la transformación en la ecuación (4) se incrementa, se requerirá un mayor número de iteraciones para encontrar la transformación optima $\tilde{T}$, o incluso puede impedir que ésta pueda ser encontrada (proceso de optimización atrapado por un óptimo local).

\section{Discusión}

Los errores obtenidos en el proceso de corrección radial para diferentes ángulos de inclinación, indican que este procedimiento puede efectuarse sujetando el endoscopio con la mano (en posición aproximadamente perpendicular con respecto al patrón), con un error final comparable con los reportados por otros métodos que necesitan de un patrón de calibración específico y de una plataforma de posicionamiento, resultando versátil y sencillo.

Es importante observar que aún cuando el error del registro de imágenes adyacentes es relativamente pequeño, este error es acumulativo, por lo que la cartografía final puede requerir de un ajuste final como podría ser un registro en las secuencias de imágenes de manera inversa a la original con lo que se esperaría que los errores fuesen promediados y distribuidos de manera uniforme en toda la secuencia. Adicionalmente, deberá en futuros trabajos tomarse en cuenta que la superficie reconstruida no se encuentra en un plano uniforme. De la misma manera, es importante mencionar que puede reducirse significativamente el tiempo para la reconstrucción al no emplear toda la secuencia de imágenes en el video original.

\section{Conclusiones}

Los resultados obtenidos muestran que la metodología propuesta permite la reconstrucción 2D de la superficie de órganos internos. El pre-procesamiento empleado permite mejorar las imágenes endoscópicas para su uso en el proceso de registro de imágenes. Como puede verse en los resultados obtenidos, la información lograda después de aplicar el filtro y la corrección de la distribución no homogénea de la iluminación permiten obtener los parámetros de la transformación global para aplicarlos posteriormente en las imágenes originales y efectuar la cartografía correspondiente.

\section{Referencias}

Asari K.V., Kumar S., Radhakrishnan D. A New Approach for Nonlinear Distortion Correction in Endoscopic Images Based on Least Squares Method. IEEE Trans. Med. Imaging, 18:345354. 1999

González R.C. Digital Image Processing. Prentice Hall. 2002.

Miranda Luna R., Blondel W.C.P.M., Daul, Hernandez Y, Posada R., Wolf D. A Simplified Method of Endoscopic Image Distortion, Correction Based on Grey Level Registration. International Conference on Image Processing (ICIP 04). Singapore, Octubre 2004. 
Shahidi R., Bax M.R., Maurer C.R., Jhonson J.A., Wilkinson E.P., Wang B., West J.P., Citardi M.J., Manwaring K.H., Khadem R. Implementation, Calibration and Accuracy Testing of ImageEnhanced Endoscopy System. IEEE Trans. Med. Imaging, 11:1524-1535. 2002.

Smith W.E., Vakil N., Maislin A. Correction of Distortion in Endoscope Images. IEEE Trans. Med. Imaging, 11:117-122. 1992.
Tian H., Srikanthan T., Asari K.V., Lam S.K. Study on the Effect of Object to Camera Distance on Polynomial Expansion Coefficients in Barrel Distortion Correction. Fifth IEEE Southwest Symposium on Image Analysis and Interpretation (SSIAI'02). New Mexico. Abril 2002.

Viola P.A. Alignment by Maximization of Mutual Information. Tesis (Doctorado en Ingeniería). Boston, MA, USA. Massachusetts Institute of Technology. 1995.

\section{Semblanza de los autores}

Rosebet Miranda-Luna. Obtuvo el grado de doctor en automatización y procesamiento de señales por el Institut National Politechnique de Lorraine (Nancy, Francia). Es profesor en el Instituto Tecnológico de la Mixteca. Sus temas de interés son el procesamiento de señales e imágenes con aplicación médica, así como la instrumentación biomédica.

Rubén Posada-Gómez. Es doctor en automatización y procesamiento de señales por el Institut National Politechnique de Lorraine (Nancy, Francia). Actualmente es profesor investigador del Instituto Tecnológico de Orizaba. Sus áreas de interés son el procesamiento de imágenes médicas, la instrumentación, el tratamiento de señales y la bioelectrónica

Giner Alor-Hernández. Es doctor en ciencias en ingeniería eléctrica con especialidad en computación por el Centro de Investigación y de Estudios Avanzados del IPN. Pertenece al Sistema Nacional de Investigadores. Actualmente es profesor investigador del Instituto Tecnológico de Orizaba.

Albino Martínez-Sibaja. Es maestro en ciencias en ingeniería electrónica con especialidad en electrónica de potencia por el CENIDET, sus líneas de investigación son las aplicaciones de la electrónica en sistemas digitales.

Guillermo Cortés-Robles. Es doctor en ciencias en sistemas industriales por el Institut National Polytechnique de Toulouse. Pertenece al Sistema Nacional de Investigadores. Actualmente es profesor investigador del Instituto Tecnológico de Orizaba. 